\title{
Pemodelan Bayesian Network untuk Menentukan Probabilitas Penyebab Pelanggaran dalam Pertandingan Karate Kumite
}

\author{
Yudha Permadya Putra ${ }^{1}$, Aradea ${ }^{2}$, Rianto ${ }^{3}$ \\ ${ }^{1,2,3}$ Jurusan Informatika, Universitas Siliwangi, Tasikmalaya, Indonesia \\ 'yudhapermadya@gmail.com, 2aradea@unsil.ac.id,rianto@unsil.ac.id
}

\section{INFORMASI ARTIKEL}

Sejarah Artikel

Diterima Redaksi: 30-12-2021

Revisi Akhir: 23-01-2022

Diterbitkan Online: 25-01-2022

\begin{tabular}{l} 
KATA KUNCI \\
\hline Bayesian Network, \\
Kumite, \\
Karate, \\
Offense, \\
Probability \\
KORESPONDENSI \\
\hline
\end{tabular}

E-mail: yudhapermadya@gmail.com

\section{Pendahuluan (hurufbesar, $10 \mathrm{pt}$, tebal)}

Pelanggaran yang terjadi pada pertandingan Kumite bisa disebabkan oleh berbagai faktor baik yang sifatnya teknis maupun non teknis, dan bisa menimpa atlet professional sekalipun. Kompleksitas aturan dalam pertandingan kumite itulah yang menjadi alasan bahwa cabang olahraga karate terlambat masuk kedalam Olimpiade. Hal ini dikarenakan banyaknya kriteria dalam menentukan suatu serangan apakah menjadi poin atau sebaliknya malah menjadikan suatu hukuman / pelanggaran.

Bayesian Network adalah model grafis yang mengodekan hubungan probabilistik antara variabel variabel yang menarik. Bayesian Network dapat menunjukkan probabilitas hubungan atara kejadian kejadian yang saling berhubungan maupun tidak berhubungan. Generalisasi Bayesian Network dapat mewakili dan memecahkan keputusan dibawah ketidakpastian yang disebut diagram pengaruh.

Penelitian dengan Bayesian Network telah digunakan dalam beberapa bidang, dalam penelitian [1] membuat model pemilihan universitas yang akan dipilih dengan beberapa variabel terkait. Sedangkan [2] menggunakannya untuk membuat aplikasi sistem pakar hewan ternak sapi untuk menarik kesimpulan penyakit apa yang diderita oleh hewan ternak sapi. Menurut[3], pengembangan framework dan model analisis risiko proyek agile dengan pendekatan Bayesian Network, digunakan sebagai tool untuk menganalisis risiko yang mempengaruhi pelaksanaan proyek. Selain dapat mengkuantitatifkan unsur ketidakpastian, Bayesian Networks juga dapat mengatasi keterbatasan data historis dan dapat diperbaharui setiap kali informasi mengenai risiko diperoleh.

Berdasarkan deskripsi hasil penelitian sebelumnya tersebut, terdapat beberapa kesesuaian persoalan yang dapat diselesaikan menggunakan Bayesian Network untuk memodelkan penyebab pelanggaran dalam pertandingan karate Kumite. Langkah awal di dalam membangun model Bayesian Network adalah membuat struktur jaringan berdasarkan studi literatur mengenai sebab akibat dari masing - masing faktor yang mempengaruhi pelanggaran. Setelah struktur jaringan terbentuk, langkah selanjutnya adalah menentukan probabilitas dari masing masing faktor. 
Penelitian ini bertujuan untuk mengetahui faktor faktor penyebab pelanggaran dalam pertandingan dan memodelkannya sehingga mampu mengantisipasi kesalahan - kesalahan atlit dalam pertandingan. Rumusan masalah yang dapat diangkat adalah "Bagaimana menentukan probabilitas penyebab pelanggaran dengan variable - variabel ketidakpastian dengan menggunakan pendekatan Bayesian Network".

\section{Penelitian Terkait}

Bayesian network dapat digunakan untuk memodelkan beragam persoalan yang ada di dunia nyata. Sebagai contoh[1] menggunakan teknik ini untuk melakukan pengembangan model keputusan dalam pemilihan universitas. Selain itu, [4] memodelkan persoalan gangguan perkembangan anak menggunakan Bayesian Network, tujuannya adalah untuk mendiagnosa kebiasaan seorang anak yang dapat berakibat pada tumbuh kembangnya . Peneliti lainnya yaitu [5] mengusulkan pendekatan menggunakan Bayesian Network untuk membuat system pendukung keputusan untuk menentukan minat dan bakat pada siswa usia SMP. Selanjutnya [6] juga menggunakan Bayesian Network untuk menghitung probabilitas penyakit sesak nafas pada bayi. Penelitian [7] yaitu penerapan Bayesian Network untuk mendiagnosis penyakit kambing yang mampu melakukan proses diagnosis berdasarkan pada gejala yang hewan kambing, dimana perhitungannya menggunakan data gejala penyakit 42 gejala dan 9 jenis penyakit kambing.

\section{Metodologi}

\subsection{ANALISA KEBUTUHAN}

Dalam analisa kebutuhan diperlukan beberapa hal yang dianggap menunjang penelitian yang dilakukan oleh penulis yaitu data atlit dan perilakunya dalam pertandingan yang diperoleh melalui pengamatan dan data yang ada pada Ketua Bidang Prestasi yang cukup berpengalaman dan berwewenang memberikan data di tempat penelitian.

\subsection{PENGUMPULAN DATA}

Data yang diambil dalam penelitian ini berdasarkan aturan pertandingan WKF dan fakta perilaku atlit di lapangan, dimana sampel yang diambil adalah dari 3 orang atlit yang saling berhadapan pada tiga partai yang berbeda, diantaranya:

Match 1:Atlit 1 vs Atlit 2

Match 2:Atlit 1 vs Atlit 3

Match 3:Atlit 2 vs Atlit 3

Dibuatlah pohon struktur Bayesian Network untuk masingmasing variable acak. Struktur Bayesian Network dibuat berdasarkan ada tidaknya keterkaitan antara prilaku atlit dengan efek yang didapatkan oleh atlit.

\subsection{PENERAPAN BAYESIAN NETWORK}

\section{A. Penentuan Variabel Acak}

Variabel acak didapat setelah mengamati fenomena dilapangan bahwa atlet yang bertanding masih banyak yang minim pengetahuan dalam aturan pertandingan, sehingga didapat variabel seperti pada tabel 1 .
Tabel. 1 Variabel Acak

\begin{tabular}{llll}
\hline No & \multicolumn{1}{c}{ Variabel } & Type & \multicolumn{1}{c}{ State } \\
\hline 1 & Tsuki & Discrete & Memukul/Tidak \\
2 & Geri & Discrete & Menendang/Tidak \\
3 & Kontak_Keras & Discrete & Ya/Tidak \\
4 & Jogai & Discrete & Keluar/Tidak \\
5 & Passivity & Discrete & Pasif/Tidak \\
6 & Uncontrolled_Attack & Discrete & Ya/Tidak \\
7 & Avoiding_Combat & Discrete & Ya/Tidak \\
8 & Yame & Discrete & Stop/Tidak \\
9 & Poin & Discrete & Yuko/Wazaari/Ippon/Tidak \\
10 & Hukuman & Discrete & Ya/Tidak \\
11 & C1 & Discrete & Ya/Tidak \\
12 & C2 & Discrete & Ya/Tidak \\
\hline
\end{tabular}

B. Menetapkan Cpt

Menetapkan CPT yaitu menentukan Conditional Probability (peluang bersyarat) antara variabel. Condotional Probability dinotasikan dengan $P(A \mid B)$ artinya peluang suatu keadaan $\mathrm{A}$, jika diketahui keadaan $\mathrm{B}$ telah terjadi. Teorema Bayes adalah sebuah pendekatan untuk ketidakpastian yang diukur oleh persamaan 1).

$$
P(A \mid B)=\frac{P(B \mid A) \cdot P(A)}{P(B)}
$$

Dimana:

$P(A \mid B)=$ peluang $\mathrm{A}$ terjadi setelah $\mathrm{B}$ terjadi (posterior probability)

$P(B \mid A)=$ peluang $\mathrm{B}$ terjadi setelah A terjadi (likelihood)

$P(A)=$ peluang kejadian $\mathrm{A}$

$P(B)=$ peluang kejadian $\mathrm{B}$

\begin{tabular}{|c|c|c|c|c|c|c|c|c|c|c|c|}
\hline Trsuki & Geri & Kontak & Jogai & Passivi & Uncoont & Avvoidi & at Yyame & Poin & Hukur & $C_{1}$ & $\mid c 2$ \\
\hline Memukul & Tidak & Ya & Tidak & Tidak & Tidak & Tidak & Stop & Tidak & & $\mathrm{Ya}$ & Tidak \\
\hline Memukul & Tidak & Tidak & $\begin{array}{l}\text { Kelluar } \\
\text { natr }\end{array}$ & Tidak & Tidak & Tidak & Stop & Tidak & $Y_{a}$ & Tidak & Ya \\
\hline $\begin{array}{l}\text { Memukul } \\
\text { Memukul }\end{array}$ & $\begin{array}{l}\text { Tidak } \\
\text { Tidakk }\end{array}$ & $\begin{array}{l}\text { Tidak } \\
\text { Tidakk }\end{array}$ & $\begin{array}{l}\text { Tidak } \\
\text { Tidalak }\end{array}$ & $\begin{array}{l}\text { Tidak } \\
\text { Tidalek }\end{array}$ & $\begin{array}{l}Y_{\mathrm{y}} \\
\text { Tididak }\end{array}$ & Tidak & $\begin{array}{l}\text { Stop } \\
\text { stop }\end{array}$ & $\begin{array}{l}\text { Titak } \\
\text { Yulko }\end{array}$ & $\begin{array}{l}{ }_{\text {Ya }} \\
\text { Tidata }\end{array}$ & Tidak & \\
\hline $\begin{array}{c}\text { Memukut } \\
\text { Memukt }\end{array}$ & $\begin{array}{l}\text { Tidiak } \\
\text { Tidak }\end{array}$ & $\begin{array}{l}\text { Tididak } \\
\text { Tidak }\end{array}$ & $\begin{array}{l}\text { Tidatk } \\
\text { Tidak }\end{array}$ & $\begin{array}{l}\text { Tidakk } \\
\text { Tidak }\end{array}$ & $\begin{array}{l}\text { Tididak } \\
\text { Tidak }\end{array}$ & $\begin{array}{l}\text { Tididak } \\
\text { Tidak }\end{array}$ & $\begin{array}{l}\text { Stopp } \\
\text { Tiddk }\end{array}$ & $\begin{array}{l}\text { Yuko } \\
\text { Tidak }\end{array}$ & $\begin{array}{l}\text { Tilatak } \\
\text { Tidak }\end{array}$ & $\begin{array}{l}\text { Tidatk } \\
\text { Tidak }\end{array}$ & $\begin{array}{l}\text { Tiddik } \\
\text { Tiddak }\end{array}$ \\
\hline & Menendarg & ya & Tidak & Tidak & & Tidak & Stop & Tidak & $\gamma_{a}$ & & \\
\hline Tiddak & Menendarg & Tidak & Keluar & Tidak & Tidak & Tidak & stop & Tidak & $\gamma_{\partial}$ & Tidak & $y_{a}$ \\
\hline Tidak & Menendarg & Tidak & Tidak & Tidak & $Y_{a}$ & Tidak & stop & Tidak & $Y_{a}$ & Tidak & Ya \\
\hline & Menendarg & Tidak & Tidak & Tidak & Tiddak & Tidak & Stop & Wazarati & Tidak & Tiddak & Tidak \\
\hline Tidak & Menendang & Tidak & Tidak & Tidak & Tidak & Tidak & stop & |ppon & Tidak & Tidak & Tidak \\
\hline & Menen & Tidak & Tidak & Tidak & & Tidak & Tidak & Tidak & Tidak & Tidak & Tidak \\
\hline Tdidak & Tdxan & Tdidar & Tentar & & Tháx & Tdad & s & T. Wak & & & \\
\hline Tidak & Tridak & Tidiak & Tidatak & Tidak & Tintak & $y_{3}$ & stop & Titak & & Tidak & ra \\
\hline Tidak & Tidak & Tidak & Tidak & Tidak & Tidak & Tidak & Tidak & Tidak & Tidak & Tidak & Tididk \\
\hline
\end{tabular}

Gambar 1. CPT

C. Implementasi Netica

Tahapan implementasi ini merupakan tahapan pada aplikasi/software Netica dimana data yang telah terkumpul akan di input ke dalam Bayesian Net yang telah di bangun dan hasilnya akan dianalisa

\section{HASIL DAN PEMBAHASAN}

Penelitian ini menggunakan data 3 orang atlit prestasi BKC Kota Tasikmalaya yang saling berhadapan pada tiga partai yang berbeda dalam perhelatan kejuaraan Selekcab di awal tahun 2020 dan menyesuaikan dengan variabel variabel yang telah ditentukan, data atlit tercatat ditampilkan pada gambar 2 .

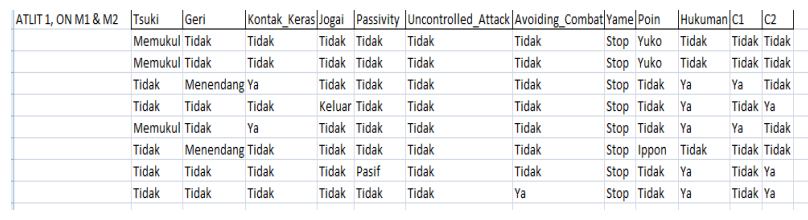

Gambar. 2 Data Atlit 1 Pada Match 1 \& Match 2 
Pada Gambar. 2 Terdapat data atlit 1 yang melakukan suatu aktivitas dan dampak dari perilaku tersebut pada Match $1 \&$ Match 2.

\begin{tabular}{|c|c|c|c|c|c|c|c|c|c|c|c|}
\hline \multirow{2}{*}{ ITLT 2, ON M1 \& M3 } & \multicolumn{2}{|c|}{\begin{tabular}{|l|l} 
Tsuki & Geri \\
\end{tabular}} & \multicolumn{2}{|c|}{ Kontak__Keras_Jogai } & \multicolumn{2}{|c|}{ PPassivity |uncontrolled_Atta } & \multicolumn{2}{|c|}{ ckl Avoiding Combat Yyame Poin } & \multicolumn{3}{|c|}{\begin{tabular}{|l|l|} 
Hukuman $\mid{ }_{1} 1$ & $\mid c 2$ \\
\end{tabular}} \\
\hline & Memukul & i Tidak & Ya & Tidoak & Tidak & Tidak & Tidak & Stop Tid & & & $\begin{array}{ll}\text { Ya } & \text { Tidak } \\
\end{array}$ \\
\hline & Memukul & & Tidak & Tidak & Tidak & $y_{a}$ & Tidak & Stop Tio & $k \quad y_{a}$ & & \\
\hline & Tidak & Menendang & & Tidak & Tidak & Yа & Tidak & Stop Tid & $k^{k} y_{a}$ & & Tidak Ya \\
\hline & Tidak & Menenda & g Tidak & Tidak & Tidak & Yа & Tidak & Stop Tid & & & \\
\hline & Memukul & il Tidak & Tidak & Tidak & Tidak & Tidak & Tidak & Stop Yul & & Iidak & Tidak Tidak \\
\hline & Tidak & Tidak & Tidak & Keluar & ir Tidak & Tidak & Tidak & Stop Tid & & & \\
\hline & Memukul & & Tidak & Tidak & Tidak & Tidak & Tidak & Stop $y_{u}$ & & fidak & Tidak Tidak \\
\hline & Memukul & & ча & Tidak & Tidak & Tidak & Tidak & Stop Tid & & & уа \\
\hline
\end{tabular}

\section{Gambar. 3 Data Atlit 2 Pada Match 1 \& Match 3}

Pada Gambar. 3 Terdapat data Atlit 2 yang melakukan suatu aktivitas dan dampak dari perilaku tersebut pada Match 1 \& Match 3 .

\subsection{MEMBANGUN STRUKTUR BAYESIAN NETWORK}

Variabel - variabel yang sudah didapat kemudian dilakukan pemodelan sesuai dengan ketergantungannya satu sama lain seperti pada gambar 5 .

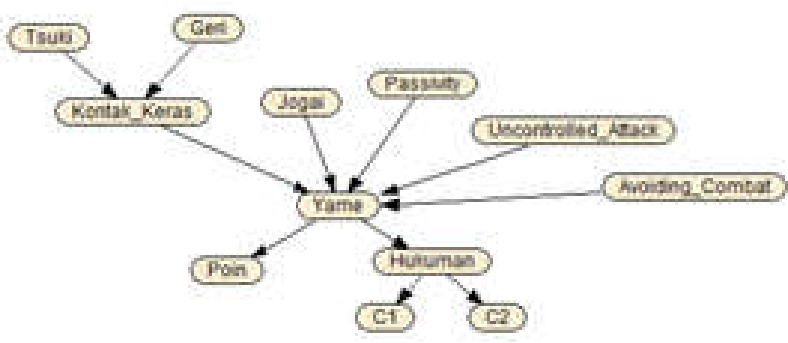

Gambar 5. Struktur Bayesian

Pemodelan tersebut menunjukkan keterkaitan antara variabel seperti contoh bahwa Kontak_Keras akan dipengaruhi oleh Tsuki (Pukulan) dan Geri (Tendangan), begitu juga untuk Yame (Wasit menghentikan pertandingan) akan mempengaruhi terhadap variabel Poin maupun Hukuman.

\subsection{MENDEFINISIKAN NODE PEMODELAN}

Membuat node dari tiap tiap variabel menggunakan Netica Tools dan mengisinya dengan type dan state seperti pada Tabel 1, dan menghubungkan keterkaitan antara variable acak satu dan lainnya atau yang biasa disebut dengan Bayesian net seperti dalam gambar 6.

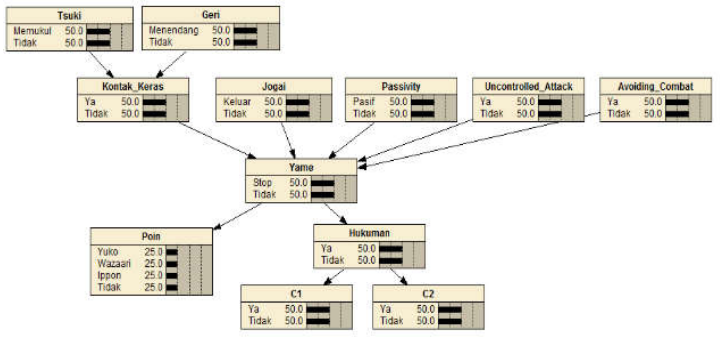

Gambar 6. BBN yang sudah siap mengcompile case

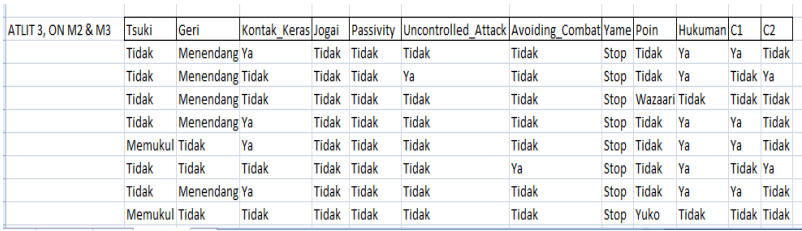

Gambar 4. Data Atlit 3 Pada Match 2 \& Match 3

Pada Gambar. 4 Terdapat data Atlit 3 yang melakukan suatu aktivitas dan dampak dari perilaku tersebut pada Match 2 \& Match 3.

\subsection{HASIL PEMROSESAN}

Didapati hasil pemrosesan terhadap data 3 orang atlit yang sudah terinterpretasikan ke dalam Bayesian Net, maka secara otomatis juga belief bars akan berubah dan menyesuaikan dengan data yang sudah diinput.

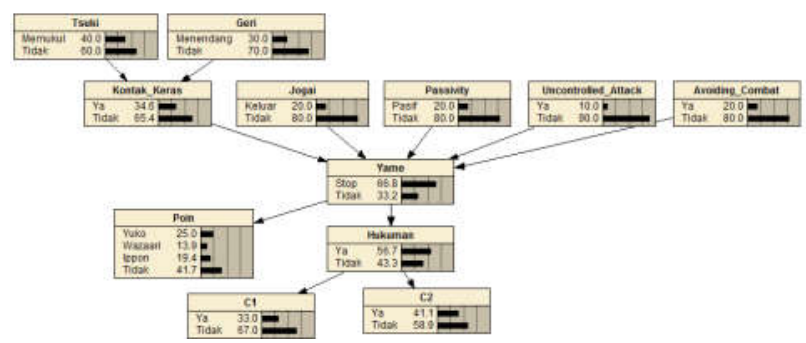

Gambar 7. BBN Atlit 1 yang sudah terupdate

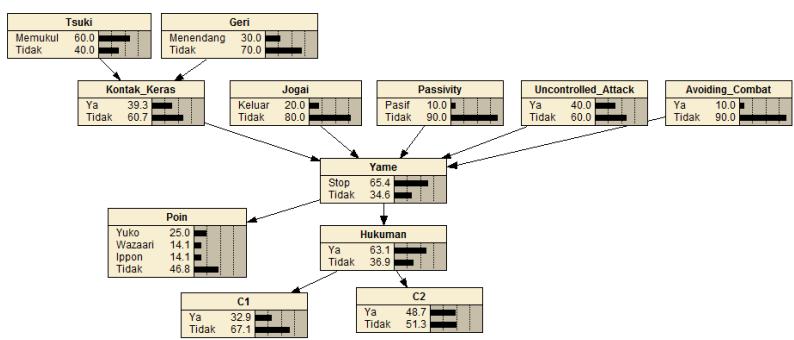

Gambar 8. BBN Atlit 2 yang sudah terupdate

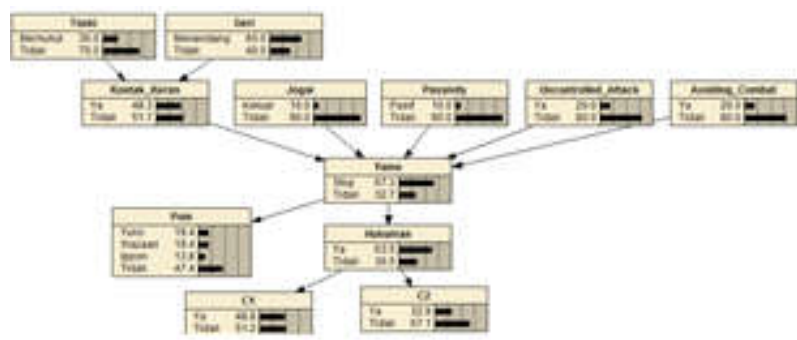

Gambar 9. BBN Atlit 3 yang sudah terupdate

Dapat kita cermati bersama pada belief bars yang telah berubah bahwa ada beberapa temuan diantaranya : 
a. Atlit 1 dan Atlit 2 dominan melakukan serangan dengan teknik Tsuki dengan persentase masing - masing $40 \%$ dan $60 \%$ dan mendapat hukuman $56,7 \%$ dan $65,4 \%$

b. Atlit 3 dominan melakukan serangan dengan teknik Geri dengan persentase $60 \%$ dan mendapat hukuman $63,5 \%$

Selain hal tersebut terdapat juga performat atlit seperti seperti ditampilkan pada gambar 10 .

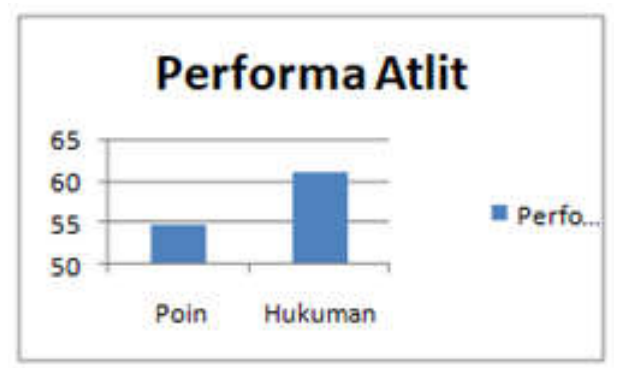

Gambar 10. Performa Atlit

Dari gambar 10 diperoleh informasi bahwa dari ketiga orang atlit rata - rata mendapatkan hukuman sebesar $61,1 \%$ atas pelanggaran yang dilakukannya, sementara rata - rata atlit yang mendapatkan nilai hanya 54,7\%. Selisih yang didapat adalah sebesar $6,4 \%$.

\subsection{ANALISIS SENSITIVITAS}

Analisis Sensitivitas digunakan untuk mengetahui faktor yang paling berpengaruh terhadap Yame / Wasit menghentikan pertandingan. Hasil sensitivity to findings pada node Yame ditampilkan pada gambar 11 .

$\begin{array}{llll}\text { Sensitivity of 'Yame' to a finding at another node: } \\ \text { Node } & \begin{array}{l}\text { Mutual } \\ \text { Info }\end{array} & \text { Percent } & \begin{array}{l}\text { Variance of } \\ \text { Beliefs }\end{array} \\ \text {--- } & 0.90872 & 100 & 0.2190368 \\ \text { Yame } & 0.06805 & 7.49 & 0.0199126 \\ \text { Poin } & 0.01829 & 2.01 & 0.0056159 \\ \text { Hukuman } & 0.00884 & 0.973 & 0.0027916 \\ \text { Avoiding_Combat } & 0.00884 & 0.973 & 0.0027916 \\ \text { Passivity } & 0.00884 & 0.973 & 0.0027916 \\ \text { Jogai } & 0.00741 & 0.815 & 0.0022811 \\ \text { Kontak_Keras } & 0.00679 & 0.748 & 0.0021119 \\ \text { Uncontrolled_Attack } & 0.00384 & 0.422 & 0.0011619 \\ \text { C2 } & 0.00039 & 0.0427 & 0.0001171 \\ \text { C1 } & 0.00011 & 0.0126 & 0.0000347 \\ \text { Tsuki } & 0.00011 & 0.0126 & 0.0000347 \\ \text { Geri } & & & \end{array}$

Gambar 11. Sensitivitas Analisis Yame

Dari hasil pada gambar 11 didapat bahwa Mutual Information Poin sebesar 0,6805 dengan persentase (7,49\%), dan untuk Hukuman sebesar 0,1829 dengan persentase sebesar $(2,01 \%)$. Dengan demikian Yame (terhentinya pertandingan) akan lebih berpengaruh pada Poin daripada terhadap Hukuman

\section{KESIMPULAN}

Bayesian Network model dalam penerapannya menentukan probabilitas penyebab pelanggaran dalam pertandingan karate kumite dapat mendefinisikan variabel (Yame) sebagai factor yang dapat mempengaruhi penyebab pelanggaran dalam pertandingan kumite dan dapat menggambarkan hubungan antara perilaku seorang atlet dengan keputusan akhir yang diambil oleh seorang wasit. Dalam struktur Bayesian Network terlihat bahwa variabel -variabel digambarkan sebagai sebuah node yang kemudian membentuk sebuah jaringan hubungan sebab akibat. Dengan fakta yang terdapat pada hasil penelitian bahwa Atlit yang melakukan Pelanggaran lebih banyak dengan selisih 6,4\%. Analisis sensitivitas yame / variabel Yame akan sangat berpengaruh terhadap temuan dari node Poin dengan Mutual Information sebesar 0,6805.

Pengembangan lebih lanjut mengenai penerapan Bayesian Network model ini, perlu ditinjau juga probabilitas seorang wasit dalam membuat suatu keputusan terhadap perilaku atlit dalam pertandingan. Sehingga apa yang diputuskan oleh seorang wasit bisa lebih presisi dan tidak merugikan maupun menguntungkan kepada salah satu pihak.

\section{DAFTAR PUSTAKA}

[1] Tutik Farihah, "Pengembangan Model Keputusan Pemilihan Universitas Menggunakan Pendekatan Bayesian Network" in (CIEHIS), 2019.

[2] Tinaliah, "Aplikasi sistem pakar untuk diagnosa penyakit hewan ternak sapi dengan bayesian network," J. Ilm. SISFOTENIKA, vol. 5, no. 1, pp. 13-24, 2015.

[3] Kusumawardani, Mufti Kenia.. "Pengembangan Framework dan Model Analisis Risiko Proyek Agile Dengan Pendekatan Bayesian Network”. Skripsi. Yogyakarta:Universitas Gadjah Mada

[4] Rita Hamdani. "Penerapan Metode Bayes dalam Mendiagnosa Gangguan Perkembangan pada Anak". Jurnal Mantik Penusa, vol. 20: hal. 70. 2016.

[5] Rusito, and Yuli Fitrianto."Sistem Pendukung Keputusan Untuk Menentukan Bakat Dan Minat Olahraga Siswa SMP Dengan Metode Bayes.” Prosiding SNST Ke-81, no. 1, 53-58, 2017.

[6] Hasniati, Hasniati, Arianti Arianti and William Philip. "Penerapan Metode Bayesian Network Model Untuk Menghitung Probabilitas Penyakit Sesak Nafas Bayi.” Jurnal Rekayasa Teknologi Informasi (JURTI). 2018

[7] Andika, Nurul, Imam, "Implementasi Metode Bayesian Network Untuk Diagnosis Penyakit Kambing", Jurnal Pengembangan Teknologi Informasi dan Teknik Komputer, Vol.2,No.9,September 2018, hlm.3032-3042

\section{BIODATA PENULIS}

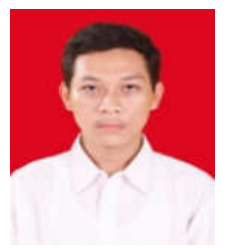

Yudha Permadya Putra

Merupakan mahasiswa jurusan informatika Universitas Siliwangi.

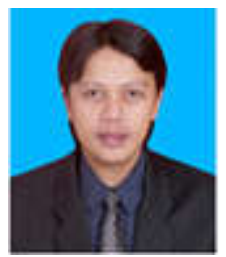

Aradea

Merupakan dosen Jurusan Informatika Universitas Siliwangi.

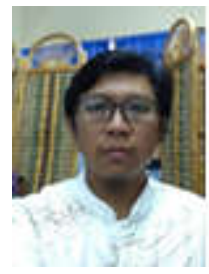

Rianto

Merupakan dosen Jurusan Informatika Universitas Siliwangi. 